\title{
PRODUÇÃO DE FITOMASSA SECA DE OITO ESPÉCIES VEGETAIS EM DUAS ÉPOCAS DE SEMEADURA NA REGIÃO NOROESTE DO ESTADO DE SÃO PAULO
}

\author{
VAZQUEZ, Gisele Herbst ${ }^{1}$ \\ LEMA, André da Cruz França ${ }^{2}$ \\ GRANZOTTO, Renato ${ }^{3}$
}

\begin{abstract}
RESUMO: Este trabalho foi realizado no município de Fernandópolis/SP com o objetivo de avaliar o potencial de produção e a composição bromatológica da fitomassa seca de oito espécies vegetais e em duas épocas de semeadura para cobertura de solo e/ou alimentação animal. As espécies estudadas foram: milheto, sorgo forrageiro, capim pé-de-galinha, mucuna cinza e preta, crotalária, lablabe e nabo forrageiro. O ensaio foi instalado em duas etapas, 12/05/2002 (época da seca) e 03/12/2002 (época das águas). Todas as fabáceas, além do milheto e do sorgo-forrageiro, produziram cerca de duas vezes mais fitomassa por área na época das águas em relação à da seca. O milheto foi superior às demais espécies nas águas, atingindo $16,7 \mathrm{t} \mathrm{ha}^{-1}$ de fitomassa seca, sendo a crotalária, a fabácea com maior produção $\left(12,1 \mathrm{t} \mathrm{ha}^{-1}\right)$. Concluiu-se que o nabo forrageiro não é indicado para a produção de fitomassa seca para cobertura do solo nas duas épocas estudadas, sendo que, nas águas, todas as demais atendem à produção mínima de fitomassa necessária para uma adequada cobertura do solo, e na seca, apenas o milheto. Visando à alimentação animal, todas as espécies estudadas podem ser utilizadas, com exceção a crotalária, a qual pode conter substâncias tóxicas, independente da época de semeadura. O milheto é a cultura de predileção por apresentar maior produção de fitomassa seca na época das águas e da seca, e boa qualidade nutricional da forragem produzida, além de possibilitar rebrota após o corte ou pastejo.
\end{abstract}

Palavras-chave: Forragem. Plantas de cobertura. Milheto. Sorgo. Crotalária.

\section{PRODUCTION OF DRY PHYTOMASS FROM EIGHT VEGETABLE SPECIES DURING TWO SOWING SEASONS IN THE NORTHWEST REGION OF SÃO PAULO STATE}

\begin{abstract}
SUMMARY: This work was done in Fernandópolis/SP, with the purpose of evaluate production potential and bromatologic composition of dry phytomass produced by eight vegetable species in two sowing seasons for soil covering and/or animal feeding. The studied species were: millet, forage sorghum, finger-millet, gray and black mucuna, sunn hemp, lablab and forage turnip. The assay was installed in two steps, May 12, 2002 (draught season) and December 3, 2002 (rain season). All the phabaceae, besides forage sorghum and millet, produced about twice more phytomass per area during the rain season compared to the draught season. The millet was superior to the other species during the rain season, reaching $16.7 \mathrm{t} \mathrm{ha}^{-1}$ of dry phytomass, being the sunn hemp the phabaceae with the biggest production $\left(12.1 \mathrm{t} \mathrm{ha}^{-1}\right)$. The forage turnip isn't indicated for the dry phytomass production for soil covering in the seasons studied. During rain season all others respond to the minimum necessary production of dry phytomass for soil covering and during the draught season, just the millet does it. Aiming animal feeding, all the species studied can be used, with restrictions to sunn hemp, which may have toxic substances, independent of sowing season. The millet is the favorite culture once it presents adequate dry phytomass production in both evaluated seasons, associated to nutritional quality of the produced forage crop, besides possibility of re-sprouting after the cut or grazing.
\end{abstract}

Keywords: Forage. Cover crops. Millet. Sorghum. Sunn hemp.

\footnotetext{
${ }^{1}$ Eng $^{\mathrm{a}} \mathrm{Agr}^{\mathrm{a}}, \mathrm{Dr}^{\mathrm{a}}$, Prof ${ }^{\mathrm{a}}$ Departamento de Fitotecnia, Tecnologia de Alimentos e Sócio Economia, Faculdade de Engenharia, UNESP, CEP 15385-000, Ilha Solteira, SP e Departamento de Produção Vegetal, Faculdade de Agronomia, UNICASTELO, CEP 15600-000, Fernandópolis, SP

${ }^{2}$ Zootecnista, Dr, Prof. da UNICASTELO, Fernandópolis, SP

${ }^{3}$ Eng. Agr., Sipcan Isagro Brasil S.A
} 


\section{INTRODUÇÃO}

De modo geral, na região noroeste do estado de São Paulo existe uma grande dificuldade para a obtenção tanto de fitomassa seca (palhada) para cobertura do solo em sistemas de plantio direto, como de forragem para ser oferecida aos animais, no período do outono/inverno. Por ser uma região quente e úmida no verão, grande parte da palhada produzida, é rapidamente decomposta; além disso, a ocorrência de outono/inverno quente e seco praticamente inviabiliza a produção de milho em safrinha, de cereais tradicionais, como a aveia e o trigo ou de culturas forrageiras, como a alfafa e a aveia preta, a não ser que sejam cultivadas sob sistemas de irrigação, o que encareceria muito o processo.

A produção de fitomassa é um requisito importante para a adoção de uma espécie em sistemas de produção conservacionista, quando se utiliza a palha para a proteção do solo no período de outono/inverno, como no caso do plantio direto, e também, quando se visa à possibilidade de fornecimento de parte do material para alimentação de animais em período de baixa disponibilidade de forragem (CARNEIRO et al., 2008). Segundo Darolt (1998), a quantidade mínima de fitomassa requerida para um eficiente sistema de rotação está em torno de 6,0 $\mathrm{tha}^{-1}$ em sistema de plantio direto.

A cobertura vegetal do solo auxilia no controle da erosão, melhora a disponibilidade de nutrientes para a cultura subseqüente (ANDREOLA et al., 2000) e os atributos físicos (CARPENEDO; MIELNICZUCK, 1990), químicos e biológicos dos solos (MEDEIROS; CALEGARI, 2008). Sua utilização também é importante por impedir o desenvolvimento de plantas daninhas (FAVERO et al., 2001), acrescentar nitrogênio ao solo através da fixação biológica (KHATOUNIAN, 2002), além de ser um requisito importante para a implantação/manutenção dos sistemas de plantio direto (CARNEIRO et al., 2008) e de integração lavoura-pecuária (CERETTA et al., 2002).

Atualmente, dentre as diversas espécies promissoras para cobertura do solo e uso na alimentação animal, destacam-se: a mucuna preta (Mucuna aterrima (Piper ; Tracy) Merr.) e a cinza (Mucuna cinereum), o lablabe (Lablab purpureum), a crotalária (Crotalaria juncea L.), o milheto (Pennisetum glaucum (L) R. Br.), o sorgo forrageiro (Sorghum bicolor (L.) Moench), o capim pé-de-galinha (Eleusine coracana (L.) Gaertn.) e o nabo forrageiro (Raphanus sativus L. var. oleiferus Metzg.).

Porém, uma espécie vegetal só expressará seu potencial produtivo se manejada na época adequada e de forma correta. Para melhorar o rendimento de um vegetal é fundamental que ocorra interação entre genótipo e ambiente. Como os elementos meteorológicos atuam diferentemente em cada época e local, a precipitação, a radiação solar, a temperatura do ar e o 
fotoperíodo, podem influenciar significativamente na produção de fitomassa (SANTOS; CAMPELO JÚNIOR, 2003).

As mucunas (Mucuna spp.) representam um grupo de plantas da família Fabaceae, que apresenta crescimento rápido e produz grande quantidade de massa verde para cobertura do solo. Podem evitar a multiplicação de nematóides e seu uso se deve a alta produtividade aliada ao baixo custo de produção (SAKAI et al., 2007). Segundo Nakagawa et al. (2007), a mucuna-preta é uma leguminosa anual ou bianual, de crescimento indeterminado, porte baixo, hábito rasteiro e com ramos trepadores vigorosos e bem desenvolvidos, podendo ser cultivada para adubação verde. Pode ser utilizada na alimentação animal como forrageira, em pastejo direto e na forma de silagem ou feno e ainda seus grãos triturados podem ser utilizados como suplemento protéico para os animais (CALEGARI, 1995). Já a mucuna cinza é originária da África e apresenta hábito de crescimento trepador (FORMENTINI, 2008). Segundo Mechi et al. (2010), essa forrageira pode ser utilizada na alimentação animal e contém em média 15,6\% de proteína bruta.

O lablabe é uma planta herbácea perene, cultivada como anual, além de ótimo adubo verde, apresenta-se como boa opção forrageira para a bovinocultura (VIEIRA et al., 2001). As sementes de lablabe podem ser usadas amplamente como fonte de alimento para o gado, melhorando a qualidade da produção graças a sua riqueza em proteínas e carboidratos (SENO et al., 1996).

A crotalária é uma leguminosa muito usada em rotação, chegando a liberar $118 \mathrm{~kg} \mathrm{ha}^{-1}$ ano $^{-1}$ de nitrogênio através da decomposição de seus resíduos culturais (TORRES et al., 2008). Entre as vantagens da utilização desta leguminosa como adubo verde, destaca-se o grande potencial de produção de massa verde com alto teor de nitrogênio, que é de fácil incorporação ao solo e decomposição (HAYASHI et al., 2002). Essa fabácea pode ser ainda empregada como forragem na alimentação de bovinos/suínos, sendo que o primeiro corte poderá ser feito aos 45-60 dias e, posteriormente, de 30 em 30 dias, não sendo recomendado o corte quando surgirem os botões florais (CALEGARI, 1995). Por outro lado, Lucena et al. (2010), relatam que vários cultivares de crotalária podem causar intoxicação em ruminantes e equinos devido à presença de alcalóides do tipo pirrolizidínicos.

As poáceas, como o milheto, por exemplo, têm se destacado pela resistência ao déficit hídrico, elevada produção de biomassa e menor custo das sementes (LARA CABEZAS et al., 2004). É cultivado após a colheita da cultura principal da safra de verão, de fevereiro a abril, para ser utilizado em pastejo por um período de 40 a 60 dias, do outono até o início do inverno. Neste período pode atingir uma produtividade de 2 a 5 arrobas de carne ha ${ }^{-1}$, além de possibilitar a vedação de parte das áreas de pastagens perenes da fazenda para uso no final da 
seca (julho a setembro), época crítica no ano para o Brasil Central (KICHEL ; MIRANDA, 2000).

O sorgo forrageiro possui características fisiológicas que permitem paralisar o crescimento ou diminuir as atividades metabólicas durante o estresse hídrico e reiniciar o crescimento quando a água se torna disponível (MASOJIDEK et al., 1991). Essa espécie vem se destacando como uma alternativa para a produção de forragem, pois além de não competir com produtos destinados ao consumo humano, suas características de cultivo e seu valor nutritivo fazem com que a cultura tenha sido estudada como sucedânea do milho, principalmente nas regiões semi-áridas e tropicais (PORTUGAL et al., 2003).

O capim-pé-de-galinha é uma planta anual, de porte ereto, com altura máxima de 1,65 $\mathrm{m}$ e perfilhamento vigoroso (FRANCISCO et al., 2007) e tem sido empregado em muitas propriedades no estado de Mato Grosso em rotação com a cultura da soja no sistema de plantio direto. Nessa região, o grão desse capim custa, em média, metade do preço do milho, portanto, sua utilização na alimentação animal poderia representar importante redução dos custos de produção (SANTOS et al., 2008). A planta apresenta ainda, tolerância à seca, a solos fracos e ácidos e é uma boa produtora de fitomassa seca, cerca de 4,6 a 8,8 $\mathrm{t} \mathrm{ha}^{-1}$ (SEGATELLI et al., 2008).

O nabo forrageiro é uma planta anual da família das crucíferas e que pode atingir de 100 a $180 \mathrm{~cm}$ de altura. Apresenta crescimento rápido e pode ser cultivado em solos ácidos e fracos (MELLO et al., 2008). A sua produtividade média da parte aérea varia de 2 a $6 \mathrm{t} \mathrm{ha}^{-1}$ de massa seca no estádio de floração (CALEGARI, 1998) e o seu uso, tem sido considerado por alguns autores, uma alternativa interessante na ciclagem de nutrientes, principalmente $\mathrm{o}$ nitrogênio, devido ao potencial reciclador de seu sistema radicular (AITA et al., 2001).

Sabendo-se da importância da produção de fitomassa com vista à cobertura do solo e/ou alimentação animal, este trabalho foi realizado com o objetivo de verificar o potencial de produção e a composição bromatológica da fitomassa seca de oito espécies vegetais produzidas em duas épocas de semeadura na região noroeste do Estado de São Paulo.

\section{MATERIAL E MÉTODOS}

O trabalho foi desenvolvido no campo experimental da Universidade Camilo Castelo Branco, Campus de Fernandópolis (SP), em um Argissolo Vermelho Amarelo eutrófico A moderado textura média-arenosa, relevo suave ondulado e ondulado (OLIVEIRA et al., 1999), localizado entre as coordenadas $20^{\circ} 16$ '50" latitude sul e 50¹7'43" longitude oeste e $20^{\circ} 18^{\prime} 05^{\prime \prime}$ de latitude sul e $50^{\circ} 16^{\prime} 26^{\prime \prime}$ de longitude oeste e a uma altitude de $520 \mathrm{~m}$. Os 
resultados das análises química e física da área foram: M.O.: $19 \mathrm{~g} . \mathrm{dm}^{-3} ; \mathrm{P}_{\text {resina }}: 6 \mathrm{mg} . \mathrm{dm}^{-3}$; $\mathrm{pH}_{\mathrm{CaCl} 2}: 5,3 ; \mathrm{K}: 4,9 \mathrm{mmol}_{\mathrm{c}} \cdot \mathrm{dm}^{-3}$; Ca: $18 \mathrm{mmol}_{\mathrm{c}} \cdot \mathrm{dm}^{-3} ; \mathrm{Mg}: 6 \mathrm{mmol}_{\mathrm{c}} \cdot \mathrm{dm}^{-3} ; \mathrm{Al}: 1 \mathrm{mmol}_{\mathrm{c}} \cdot \mathrm{dm}^{-3}$; $\mathrm{H}+\mathrm{Al}: 18 \mathrm{mmol}_{\mathrm{c}} \cdot \mathrm{dm}^{-3}$; SB: 28,9 mmol $\cdot \mathrm{dm}^{-3}$; CTC: 46,9 $\mathrm{mmol}_{\mathrm{c}} \cdot \mathrm{dm}^{-3}$; V: 61,6\%; Areia: 725 g.kg-1 ; Silte: 217 g.kg ${ }^{-1}$ e Argila: 58 g. $\mathrm{kg}^{-1}$. O clima da região, de acordo com a classificação de Köppen, é subtropical úmido, Aw, com inverno seco e ameno e verão quente e chuvoso (ROLIM et al., 2007). De acordo com a EMBRAPA (2007) a região é caracterizada por um período de 6 meses do ano com déficit hídrico e temperatura média de $23,5{ }^{\circ} \mathrm{C}$. Os dados meteorológicos coletados no decorrer da condução do experimento estão apresentados na Figura 1.

Os fatores avaliados foram oito espécies vegetais (mucuna preta, mucuna cinza, lablabe, crotalária, milheto cv. BN-2, sorgo forrageiro, capim pé-de-galinha e nabo forrageiro cv. CATI AL-1000), semeadas em duas épocas: estação seca (12/05/2002) e chuvosa (03/12/2002). O delineamento experimental utilizado foi o de blocos casualizados em esquema fatorial $8 \times 2$ ( 8 espécies e 2 épocas de semeadura), com quatro repetições. As parcelas possuíam as dimensões totais de 15 x 3,5 m, sendo considerado como área útil $13 \mathrm{x}$ $2,5 \mathrm{~m}$.

O preparo do solo foi realizado com uma aração e duas gradagens e, em seguida, as parcelas foram sulcadas de modo manual nos espaçamentos de $0,30 \mathrm{~m}$ para o capim pé-degalinha, 0,40 m para o milheto, 0,50 m para a crotalária e 0,60 m para as mucunas, lablabe e sorgo e adubadas com $200 \mathrm{~kg} \mathrm{ha}^{-1}$ da fórmula 4-14-8, de acordo com o resultado da análise do solo.

A semeadura foi manual e o cálculo do número de sementes por metro foi feito levando-se em consideração o valor cultural das sementes, além de um adicional de $50 \%$ na sua quantidade na época da seca e de $20 \%$ na das águas, devido às condições desfavoráveis para a germinação, principalmente na época seca. Desse modo, as populações obtidas, por hectare foram de 165.000 plantas para mucuna preta, cinza e lablabe; 250.000 plantas para nabo forrageiro; 330.000 plantas para sorgo forrageiro; 400.000 plantas para crotalária e 500.000 plantas para milheto. Após um mês da emergência, para as duas épocas, executou-se o desbaste, estabelecendo uma densidade de 10 plantas $\mathrm{m}^{-1}$ para a mucuna preta, mucuna cinza, lablabe e nabo forrageiro, 20 plantas $\mathrm{m}^{-1}$ para a crotalária, milheto e sorgo forrageiro. $\mathrm{O}$ capim pé-de-galinha não foi desbastado permanecendo com a densidade inicial que foi de 12 $\mathrm{kg} \mathrm{ha}^{-1}$ de sementes (cerca de 150 plantas $\mathrm{m}^{-1}$ ). 


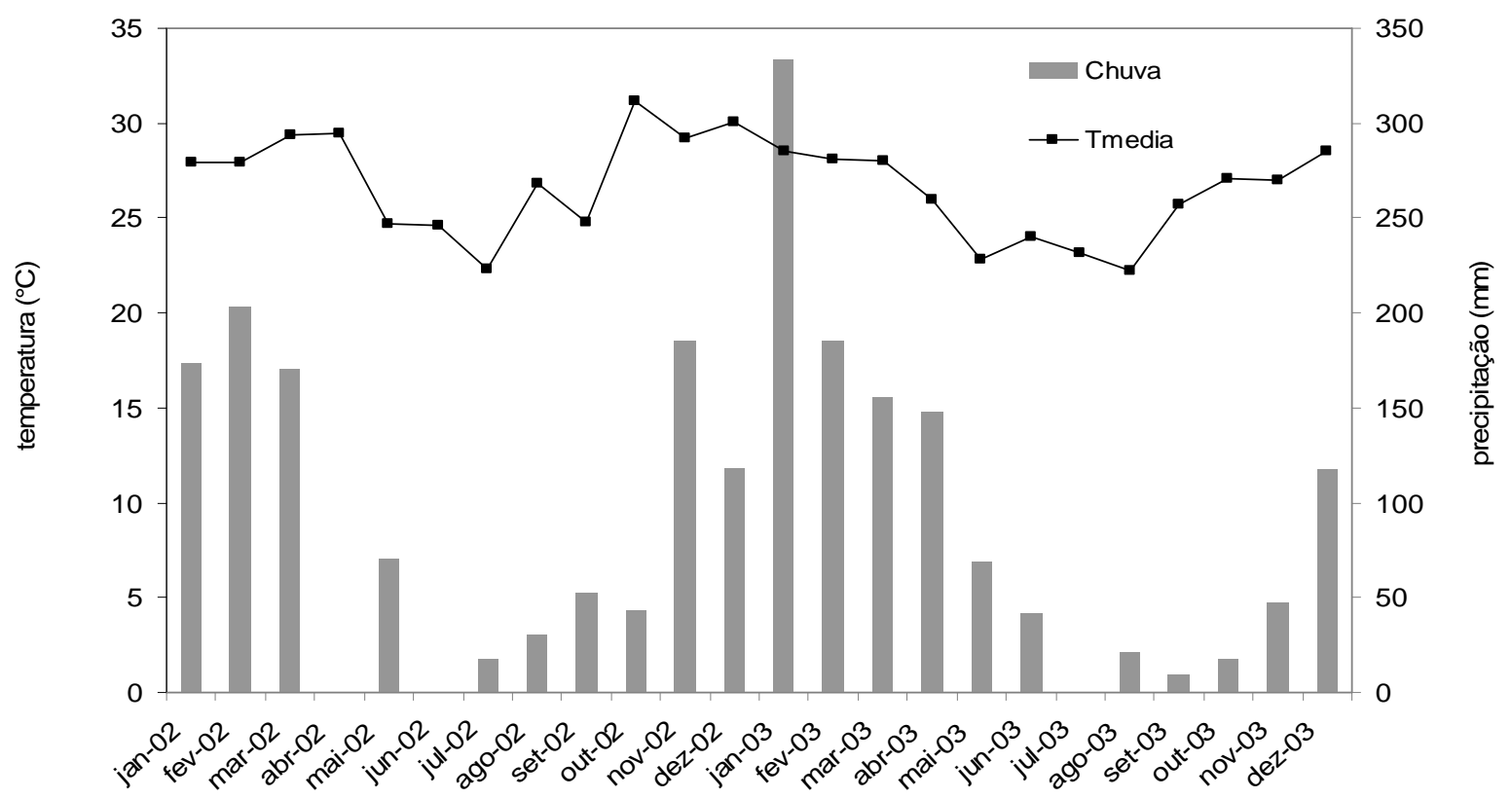

FIGURA 1. Médias mensais de temperatura $\left({ }^{\circ} \mathrm{C}\right)$ e precipitação $(\mathrm{mm})$ nos anos de 2002 e 2003 em Fernandópolis, SP.

Fonte: Informações obtidas no Escritório de Desenvolvimento Rural de Fernandópolis (CATI/SP).

As fabáceas foram inoculadas com Bradyrhizobium spp, estirpe SEMIA 6158, momentos antes da semeadura (500 g do inoculante turfoso para $50 \mathrm{~kg}$ da semente). Não foram feitas adubações de cobertura.

Os fatores estudados foram avaliados nas duas épocas estudadas através das seguintes variáveis: número de dias para o florescimento (contagem dos dias necessários ao florescimento de $50 \%$ das plantas), população de plantas ha ${ }^{-1} \operatorname{logo}$ após o desbaste e na colheita (contagem direta de todas as plantas da área útil), altura total de plantas (média de 10 plantas escolhidas ao acaso dentro da parcela útil após o florescimento), produção de fitomassa seca na época do florescimento (foram cortadas rente ao solo, em quatro diferentes locais dentro da parcela útil todas as plantas desenvolvidas em uma área de $0,25 \mathrm{~m}^{2}$, após o material foi secado em estufa com circulação e renovação forçada de ar, a $65^{\circ} \mathrm{C}$ por $72 \mathrm{~h}$, quando então se procedeu a pesagem) e composição bromatológica, com realização de análises dos teores de matéria seca (MS), matéria orgânica (MO), proteína bruta (PB), fibra bruta (FB) e extrato etéreo (EE), segundo Silva (1998) e estimativa dos teores de nutrientes digestíveis totais (NDT), calculados a partir de Kearl (1982). Todas as avaliações bromatológicas foram realizadas na época do florescimento.

Os fatores foram submetidos à análise de variância pelo teste $\mathrm{F}$ e as médias comparadas entre si pelo teste de Tukey a $5 \%$ de probabilidade. Não foi realizada a análise estatística para as médias de população de plantas. 


\section{RESULTADOS E DISCUSSÃO}

O número de dias para o florescimento da mucuna preta, mucuna cinza, milheto, sorgo forrageiro e capim pé-de-galinha não apresentou variações nas duas épocas estudadas, ocorrendo 60 dias após a emergência (DAE), mesmo havendo uma variação no total de precipitação de $88,9 \mathrm{~mm}$ para 456,6 $\mathrm{mm}$ na época da seca para a das águas, respectivamente (Figura 1). De acordo com as informações de Santos e Campelo Júnior (2003), a mucuna apresenta alta correlação da soma térmica (graus-dias) com o número de dias para florescer, o mesmo ocorre com as poáceas segundo Fornasieri Filho (2007), não havendo interferência do fotoperíodo.

A crotalária e o lablabe, na época da seca, atingiram 50\% das plantas florescidas aos 60 DAE, já nas águas, esse estádio ocorreu aos 120 e aos 150 DAE, para cada uma das espécies, respectivamente. A C. juncea por responder ao fotoperíodo e comportar-se como planta de dias curtos (valor crítico de 13,6 h segundo Santos e Campelo Júnior, 2003) antecipou o florescimento quando a semeadura foi efetuada em maio, período de outono em que os dias mostram-se inferiores a $12 \mathrm{~h}$ de luz na latitude do experimento. $\mathrm{O}$ lablabe mostrou também ser uma espécie de dias curtos, havendo, segundo Vieira et al. (2001), cultivares de dias curtos, longos e neutros. O nabo forrageiro teve o período necessário ao florescimento reduzido na época das águas (30 DAE) em relação à seca (60 DAE) por ser uma espécie de inverno, onde altas temperaturas aceleram o seu ciclo (CATI, 2000).

Para todas as espécies semeadas houve redução na população de plantas na colheita em relação à população inicial após o desbaste (Tabela 1). Na época da seca ocorreu maior perda de plantas quando comparada às águas, devido à ocorrência de fatores climáticos desfavoráveis, como, por exemplo, a deficiência hídrica.

Na comparação das médias de altura de plantas e produção de fitomassa seca (FS) foi verificado efeito significativo da interação dos fatores espécies e épocas de semeadura (Tabela 1). O milheto e o sorgo forrageiro diferiram das demais e apresentaram, nas duas épocas de semeadura, as maiores alturas de plantas. Com exceção do capim pé-de-galinha que não apresentou diferenças estatísticas e do nabo forrageiro que mostrou maior altura na época da seca, todas as demais espécies apresentaram altura significativamente maior no período das águas, o que pode ser atribuído às condições climáticas (precipitação, temperatura e radiação solar). Para a crotalária e o lablabe, além dos fatores acima mencionados, pode-se destacar ainda o maior período de desenvolvimento vegetativo até o florescimento na época das águas, o qual pode ter contribuído para a maior altura de plantas. $\mathrm{O}$ nabo forrageiro, por ser uma 
forrageira de inverno (CATI, 2000), apresentou maior desenvolvimento no período da seca (outono/inverno), com consequente maior altura de plantas.

Quanto à produção de FS, o milheto na época da seca superou estatisticamente todas as fabáceas e o nabo forrageiro, não havendo, porém, diferenças com as outras poáceas avaliadas (Tabela 1). Já nas águas, o sorgo produziu 16,7 $\mathrm{t} \mathrm{ha}^{-1}$, superando todas as demais espécies. Por sua vez, a análise entre épocas de semeadura mostrou maior produção de FS nas águas quando comparada ao período da seca para todas as espécies, com exceção do nabo forrageiro. Todas as espécies estudadas com exceção do capim-pé-de-galinha e do nabo forrageiro produziram mais do que o dobro de FS no período das águas em relação ao da seca, o que pode estar associado às exigências climáticas e a sensibilidade das espécies ao déficit hídrico.

Tabela 1. Médias da população, altura de plantas e produção de fitomassa seca de 8 espécies de plantas de cobertura semeadas em duas épocas em Fernandópolis/SP.

\begin{tabular}{|c|c|c|c|c|c|c|c|}
\hline \multirow[t]{2}{*}{ Espécie } & \multicolumn{3}{|c|}{$\begin{array}{c}\text { População } \\
\left(\text { plantas ha }^{-1}\right)\end{array}$} & \multicolumn{2}{|c|}{$\begin{array}{l}\text { Altura de plantas } \\
(\mathrm{m})\end{array}$} & \multicolumn{2}{|c|}{$\begin{array}{l}\text { Fitomassa seca } \\
\qquad\left(\mathrm{t} \mathrm{ha}^{-1}\right)\end{array}$} \\
\hline & $\begin{array}{l}\text { Inicial após } \\
\text { desbaste } \\
\text { Seca/Águas }\end{array}$ & $\begin{array}{l}\mathrm{Na} \\
\text { colheita } \\
\text { Seca }\end{array}$ & $\begin{array}{l}\mathrm{Na} \\
\text { colheita } \\
\text { Águas }\end{array}$ & Seca & Águas & Seca & Águas \\
\hline Milheto & 500.000 & 450.000 & 475.000 & $1,39 \mathrm{Ab}$ & $2,47 \mathrm{Aa}$ & $6,0 \mathrm{Ab}$ & $13,6 \mathrm{Ba}$ \\
\hline Sorgo forrageiro & 330.000 & 250.000 & 300.000 & $1,59 \mathrm{Ab}$ & $2,70 \mathrm{Aa}$ & $4,7 \mathrm{ABb}$ & $16,7 \mathrm{Aa}$ \\
\hline Pé-de-galinha & ---- & ---- & ---- & $0,69 \mathrm{BCa}$ & $0,75 \mathrm{Da}$ & $3,9 \mathrm{ABb}$ & $6,8 \mathrm{Ca}$ \\
\hline Mucuna preta & 165.000 & 110.000 & 116.000 & $0,50 \mathrm{Cb}$ & $1,19 \mathrm{Ca}$ & $2,5 \mathrm{Bb}$ & $6,9 \mathrm{Ca}$ \\
\hline Mucuna cinza & 165.000 & 116.000 & 150.000 & $0,51 \mathrm{Cb}$ & $1,21 \mathrm{Ca}$ & $2,6 \mathrm{Bb}$ & $7,5 \mathrm{Ca}$ \\
\hline Crotalária & 400.000 & 360.000 & 380.000 & $0,90 \mathrm{Bb}$ & $2,08 \mathrm{Ba}$ & $2,5 \mathrm{Bb}$ & $12,1 \mathrm{Ba}$ \\
\hline Lablabe & 165.000 & 133.000 & 133.000 & $0,51 \mathrm{Cb}$ & $1,05 \mathrm{Ca}$ & $2,4 \mathrm{Bb}$ & $7,4 \mathrm{Ca}$ \\
\hline Nabo forrageiro & 250.000 & 175.000 & 200.000 & $0,90 \mathrm{Ba}$ & $0,65 \mathrm{Db}$ & 2,7 Ba & $2,5 \mathrm{Da}$ \\
\hline
\end{tabular}

${ }^{1}$ Valores seguidos das mesmas letras, maiúsculas nas colunas e minúsculas nas linhas, não diferem entre si pelo teste de Tukey, a 5\% de probabilidade

A análise dos valores obtidos de FS das poáceas mostra que o valor alcançado pelo milheto na época da seca foi idêntico ao relatado por Fontaneli (2003) de 6,0 t ha ${ }^{-1}$ em semeaduras tardias (fevereiro) e superou o obtido por Torres et al. (2008) de 3,6 $\mathrm{t} \mathrm{ha}^{-1} \mathrm{em}$ área semeada em abril em Uberaba/MG. No período das águas, Scheffer-Basso et al. (2004) obtiveram produção de $13 \mathrm{t} \mathrm{ha}^{-1}$, próxima à obtida nesse experimento, enquanto Suzuki; Alves (2006), Boer et al. (2007) e Torres et al. (2008) observaram valores inferiores $(11,8,10,8$ e $10,3 \mathrm{t} \mathrm{ha}^{-1}$, respectivamente) e Carneiro et al. (2008), uma maior produção $\left(16,4 \mathrm{t} \mathrm{ha}^{-1}\right)$. A produção de FS do sorgo forrageiro na época da seca foi semelhante à relatada por Torres et al. (2008) de 4,0 t ha ${ }^{-1}$; já nas águas, Torres et al.(2008) e Meschede et al. (2007), encontraram 
valores inferiores ao desse experimento $\left(7,1 \mathrm{e} 11,9 \mathrm{t} \mathrm{ha}^{-1}\right.$, respectivamente). O capim pé-degalinha, na época das águas, atingiu uma produção de FS próxima a média de $6,13 \mathrm{t}$ ha $^{-1}$ relatada por Segatelli et al. (2008) em Piracicaba/SP, sendo, porém, inferior à obtida por Boer et al. (2007) de 8,7 t ha ${ }^{-1}$ em Rio Verde/GO. Na época da seca, o capim pé-de-galinha apresentou uma produção de FS cerca de $47 \%$ inferior a das águas.

Para as fabáceas, não houve diferenças estatísticas quanto à produção de FS na época da seca; nas águas, a crotalária superou as demais, também em função do maior período de desenvolvimento vegetativo (150 dias até o florescimento). A produção de FS da mucuna preta nas águas esteve próxima à relatada por Suzuki; Alves (2006) de 7,5 t ha ${ }^{-1}$ e superou os valores de 2,6 e 3,5 t ha ${ }^{-1}$ obtidos por Sodré Filho et al. (2008) e Amabile et al. (2000), respectivamente. Já na época da seca, o valor produzido foi inferior ao descrito por Amabile et al. (2000) em semeadura efetuada em março em Senador Canedo/GO (4,0 t ha $\left.{ }^{-1}\right)$. A mucuna cinza apresentou produções de FS semelhantes às da mucuna preta nas duas épocas. Para essa espécie, Nascimento; Silva (2004) relataram valores de 6,5 $\mathrm{t} \mathrm{ha}^{-1}$ nas águas. A produção da crotalária na seca foi inferior às alcançadas por Amabile et al. (2000) de 6,0 t ha ${ }^{-1}$ e Torres et al. (2008) de 3,7 $\mathrm{t} \mathrm{ha}^{-1}$. Nas águas, o valor obtido foi superior aos descritos por Nascimento; Silva (2004), Sodré Filho et al. (2008), Torres et al. (2008), Meschede et al. (2007), Carneiro et al. (2008) e Suzuki; Alves (2006) de 2,0, 2,1, 3,9, 7,5, 8,0 e 9,8 t ha ${ }^{-1}$, respectivamente, e inferior ao de Amabile et al. (2000) de 17,3 $\mathrm{t} \mathrm{ha}^{-1}$. O lablabe na época das águas apresentou maior produção de FS que a relatada por Nascimento; Silva (2004) de 4,2 t $\mathrm{ha}^{-1}$ e menor que a de Carneiro et al. (2008) de 8,7 $\mathrm{t} \mathrm{ha}^{-1}$.

Para o nabo forrageiro, os valores obtidos para a FS, nas duas épocas, foram semelhantes aos de Carvalho et al. (2007) de 2,5 $\mathrm{t} \mathrm{ha}^{-1}$, obtido em semeadura em outubro em Castro/PR, mas foram inferiores ao relatado por Carneiro et al. (2008) de 5,3 $\mathrm{t} \mathrm{ha}^{-1} \mathrm{em}$ março em Jataí/GO.

A produção de fitomassa é um requisito importante para a adoção de uma espécie em sistemas de produção conservacionista, como no caso do plantio direto (CARNEIRO et al., 2008). No período das águas apenas a produção do nabo forrageiro não atingiu a quantidade de fitomassa de 6,0 t ha ${ }^{-1}$, citada por Darolt (1998) como a quantidade mínima para um sistema eficiente de rotação de culturas. Já no período das águas, apenas o milheto atingiu a produção de fitomassa mínima recomendada.

Nas Tabelas 2 e 3 estão apresentados os valores referentes à composição bromatológica das espécies vegetais estudadas para as duas épocas de semeadura. A determinação dos teores de matéria seca original e matéria orgânica são importantes parâmetros na determinação do consumo de matéria seca pelos animais. Segundo o NRC 
(1989), existe uma relação negativa entre o consumo e o teor de umidade da dieta. Os teores médios de matéria seca original - MSO (Tabela 2) foram maiores na época da seca em relação ao das águas $(34,8 \%$ x $22 \% \mathrm{MSO}$, respectivamente). Isso se deve, de forma geral, ao menor conteúdo de água presente nas plantas durante o período seco do ano.

Com relação ao teor de matéria orgânica (MO), o nabo forrageiro diferiu dos demais e apresentou o menor valor, independente da época de semeadura. $\mathrm{Na}$ época da seca, o sorgo apresentou teor, para essa variável, semelhante àqueles obtidos para o milheto, mucuna cinza e crotalária. Os teores médios de MO foram bem próximos nas duas épocas avaliadas $(91,1 \%$ e $91,7 \%$ respectivamente na seca e nas águas).

Tabela 2. Valores porcentuais de matéria seca original (MSO) e de matéria orgânica (MO) de 8 espécies vegetais semeadas em duas épocas em Fernandópolis/SP.

\begin{tabular}{|c|c|c|c|c|}
\hline \multirow{2}{*}{ Espécies } & \multicolumn{2}{|c|}{$\mathrm{MSO}(\%)$} & \multicolumn{2}{|c|}{$\mathrm{MO}^{1}(\%)$} \\
\hline & seca & águas & Seca & Águas \\
\hline Milheto & 46,9 Aa & $22,4 \mathrm{ABb}^{2}$ & $93,5 \mathrm{Aa}$ & $92,8 \mathrm{Aba}$ \\
\hline Sorgo Forrageiro & $35,8 \mathrm{ABa}$ & $23,9 \mathrm{ABb}$ & 95,4 Aa & 94,9 Аа \\
\hline Pé de galinha & 46,9 Аа & $26,2 \mathrm{Ab}$ & $93,1 \mathrm{Aa}$ & $90,3 \mathrm{BCa}$ \\
\hline Mucuna Preta & $25,2 \mathrm{Ba}$ & $23,3 \mathrm{ABa}$ & $95,0 \mathrm{Aa}$ & $91,1 \mathrm{BCb}$ \\
\hline Mucuna Cinza & $24,3 \mathrm{Ba}$ & $19,9 \mathrm{BCb}$ & $95,2 \mathrm{Aa}$ & $92,2 \mathrm{ABb}$ \\
\hline Crotalária & 46,9 Аа & $26,4 \mathrm{Aa}$ & $94,1 \mathrm{Aa}$ & $92,9 \mathrm{ABb}$ \\
\hline Lablabe & $27,1 \mathrm{Ba}$ & $18,0 \mathrm{BCa}$ & $94,0 \mathrm{Aa}$ & $88,1 \mathrm{CDb}$ \\
\hline Nabo forrageiro & $25,5 \mathrm{Ba}$ & $16,0 \mathrm{Cb}$ & $73,5 \mathrm{Ba}$ & $86,3 \mathrm{Da}$ \\
\hline Média & 34,8 & 22,0 & 91,7 & 91,1 \\
\hline CV\% & & & & \\
\hline
\end{tabular}

${ }^{1}$ Teores expressos na matéria seca total.

${ }^{2}$ Valores seguidos das mesmas letras, maiúsculas nas colunas e minúsculas nas linhas, não diferem entre si pelo teste de Tukey, a 5\% de probabilidade

Para os parâmetros nutricionais (Tabela 3), os mesmos apresentaram variação dentro do esperado. Os teores de proteína bruta (PB) foram superiores na época das águas em relação aos da seca para o sorgo forrageiro, mucuna preta e cinza, crotalária e lablabe. A redução no teor protéico ocorrida no período da seca foi em média de 44,0\% para as espécies milheto, sorgo forrageiro, capim-pé-de-galinha, mucunas preta e cinza e lablabe. Na crotalária foi verificada uma redução de apenas $15,3 \%$, enquanto que para o nabo forrageiro foi verificado um aumento de $45 \%$ no teor protéico, evidenciando se tratar de uma planta de dias curtos.

De forma geral, os teores de fibra bruta (FB) aumentaram no período da seca em relação ao das águas. O aumento observado foi em média de $27 \%$ para o sorgo forrageiro e 
para a crotalária, de $34 \%$ para o milheto, de $44 \%$ para o capim-pé-de-galinha e para as mucunas e de $66 \%$ para o lablabe. Já o nabo forrageiro apresentou uma redução de $38 \%$ no teor de fibra da época das águas para a da seca. As forrageiras com maiores teores de FB na época da seca foram o lablabe $(38,8 \%)$, a crotalária $(38,2 \%)$, o milheto $(37,7 \%)$ e as mucunas preta $(34,1 \%)$ e cinza $(34,6 \%)$, que não diferiram entre si. Já na época das águas, os maiores valores foram observados na crotalária $(29,9 \%)$ e no milheto $(28 \%)$. O teor de FB tem relação inversa com o consumo dos animais. Desse modo, quanto maior o teor de FB menor será o consumo dos animais, devido ao efeito de enchimento proporcionado pela fibra presente nos alimentos. Pelos dados obtidos pode-se entender o porquê que na época da seca é muito difícil manter os animais ganhando peso em sistema de pastejo sem suplementação. Os animais apresentam menor ingestão de alimentos pelo aumento dos teores de MS e diminuem a ingestão de nutrientes, o que acaba levando a perda de peso.

Apenas o milheto apresentou variação no teor de extrato etéreo (EE) entre as duas épocas de semeadura, sendo superior no período das águas. Nesta época, a mucuna preta apresentou teores dessa fração semelhantes aos do capim-pé-de-galinha, mucuna cinza, lablabe e nabo forrageiro, diferindo das demais. Para a época da seca, o milheto e o sorgo forrageiro apresentaram menores teores em relação à mucuna preta e ao nabo forrageiro.

Para a fração nutrientes digestíveis totais (NDT), não foram observadas variações entre as diferentes épocas de semeadura, com exceção da mucuna cinza. Na época das águas, o milheto apresentou teor de NDT semelhante ao do sorgo forrageiro, capim-pé-de-galinha, mucuna cinza, lablabe e nabo forrageiro. Já na época da seca, essa similaridade não foi mais observada para o capim-pé-de-galinha e para a mucuna cinza, permanecendo, porém, para as demais forrageiras.

Os teores de MSO, MO, PB e FB obtidos neste experimento para o milheto, sorgo forrageiro e lablabe foram semelhantes àqueles apresentados por Valadares Filho et al. (2006) e o de PB do capim-pé-de-galinha, de 7,5\% para a época da seca, ao de Azevedo; Nascimento (2002), cujo valor foi de $7,06 \%$.

Tabela 3. Composição bromatológica de 8 espécies vegetais semeadas em Fernandópolis/SP nas épocas da seca e das águas com os nutrientes expressos na matéria seca total. (Continua)

\begin{tabular}{|c|c|c|c|c|c|c|c|c|}
\hline \multirow{2}{*}{ Espécies } & \multicolumn{2}{|c|}{ PB (\%) } & \multicolumn{2}{|c|}{ FB $(\%)$} & \multicolumn{2}{|c|}{$\mathrm{EE}(\%)$} & \multicolumn{2}{|c|}{ NDT (\%) } \\
\hline & seca & águas & seca & águas & seca & águas & seca & Águas \\
\hline Milheto & $6,2 \mathrm{DEa}$ & $10,8 \mathrm{Ca}$ & $37,7 \mathrm{ABa}$ & $28,0 \mathrm{ABb}$ & $2,6 \mathrm{Bb}$ & $5,6 \mathrm{BCa}$ & $53,3 \mathrm{Ba}$ & $59,9 \quad \mathrm{Ca}$ \\
\hline Sorgo Forrageiro & $5,4 \mathrm{~Eb}$ & $8,3 \mathrm{Ca}$ & $32,1 \mathrm{BCa}$ & $25,3 \mathrm{BCb}$ & 2,7 Ba & $5,6 \mathrm{BCa}$ & $60,3 \mathrm{Ba}$ & $\begin{array}{l}62,1 \\
\mathrm{BCa}\end{array}$ \\
\hline Pé de galinha & 7,5 CDEa & $12,4 \mathrm{Ca}$ & $26,7 \mathrm{Ca}$ & $18,6 \mathrm{Db}$ & $6,6 \mathrm{ABa}$ & 6,3 ABCa & $67,2 \mathrm{Aa}$ & $\begin{array}{c}70,6 \\
\mathrm{ABCa}\end{array}$ \\
\hline Mucuna Preta & $10,7 \mathrm{CDb}$ & $23,9 \mathrm{Aa}$ & $34,1 \mathrm{ABa}$ & $23,5 \mathrm{Cb}$ & 7,7 Aa & $10,0 \mathrm{Aa}$ & $69,5 \mathrm{Aa}$ & $77,3 \mathrm{Aa}$ \\
\hline
\end{tabular}


Tabela 3. Composição bromatológica de 8 espécies vegetais semeadas em Fernandópolis/SP nas épocas da seca e das águas com os nutrientes expressos na matéria seca total. (Conclusão)

\begin{tabular}{|c|c|c|c|c|c|c|c|c|}
\hline Mucuna Cinza & $10,8 \mathrm{CDb}$ & $22,3 \mathrm{ABa}$ & $34,6 \mathrm{ABa}$ & $\begin{array}{l}24,2 \\
\mathrm{BCb}\end{array}$ & 4,4 $\mathrm{ABa}$ & $8,3 \mathrm{ABCa}$ & $66,6 \mathrm{Ab}$ & $\begin{array}{c}73,9 \\
\mathrm{ABCa}\end{array}$ \\
\hline Crotalária & $16,6 \mathrm{Bb}$ & $19,6 \mathrm{ABa}$ & $38,2 \mathrm{Aa}$ & 29,9 Аа & $6,6 \mathrm{ABa}$ & $5,1 \mathrm{Ca}$ & $65,8 \mathrm{ABa}$ & 75,1 Aba \\
\hline Lablabe & $11,4 \mathrm{Cb}$ & $19,2 \mathrm{ABa}$ & $38,8 \mathrm{Aa}$ & $23.4 \mathrm{Cb}$ & $5,9 \mathrm{ABa}$ & 6,9 $\mathrm{ABCa}$ & $62,5 \mathrm{ABa}$ & 65,3 \\
\hline Nabo Forrageiro & $25,6 \mathrm{Aa}$ & $17,6 \mathrm{Bb}$ & $14,4 \mathrm{Db}$ & $23,3 \mathrm{Ca}$ & $7,7 \mathrm{Aa}$ & $9,4 \mathrm{ABa}$ & $60,6 \mathrm{ABa}$ & $\begin{array}{c}\mathrm{ABCa} \\
66,9 \\
\mathrm{ABCa}\end{array}$ \\
\hline CV \% & & & & & & & & \\
\hline
\end{tabular}

${ }^{\mathrm{T}}$ Valores seguidos das mesmas letras, maiúsculas nas colunas e minúsculas nas linhas, não diferem entre si pelo teste de Tukey, a 5\% de probabilidade

Considerando que teores de PB inferiores a 7\% são limitantes à produção animal por implicarem em menor consumo voluntário, redução na digestibilidade e balanço nitrogenado negativo (MINSON, 1990). Pelos teores nutricionais apresentados, pode-se inferir que todas as espécies forrageiras estudadas podem ser oferecidas como alimento para animais de produção, como bovinos de corte e de leite, em especial para a época da seca, quando as pastagens naturalmente estão com queda acentuada na quantidade e na qualidade da forragem produzida. Segundo Calegari (2009), a única restrição é com relação à crotalária, a qual não deve ser oferecida na alimentação animal, uma vez que pode conter constituintes tóxicos.

\section{CONCLUSÃO}

O milheto, sorgo forrageiro, capim-pé-de-galinha, lablabe, crotalária, mucuna preta e cinza são recomendados para a produção de palhada para uma adequada cobertura do solo em um sistema de plantio direto na época das águas, enquanto na época na seca, recomenda-se o cultivo do milheto. O nabo forrageiro não é indicado para a produção de fitomassa seca na região Noroeste de São Paulo.

Visando à alimentação animal, todas as espécies estudadas podem ser utilizadas, com exceção a crotalária, a qual pode conter substâncias tóxicas, independente da época de semeadura. $\mathrm{O}$ milheto é a cultura de predileção por apresentar maior produção de fitomassa seca na época das águas e da seca, e boa qualidade nutricional da forragem produzida, além de possibilitar rebrota após o corte ou pastejo. 


\section{REFERÊNCIAS}

AITA, C. et al. Plantas de cobertura de solo como fontes de nitrogênio ao milho. Revista Brasileira de Ciência do Solo, v.25, p.157-1165, 2001.

AMABILE, R.F.; FANCELLI, A.L.; CARVALHO, A.M. Comportamento de espécies de adubos verdes em diferentes épocas de semeadura e espaçamentos na região dos cerrados. Pesquisa Agropecuária Brasileira, v.35, n.1, p.47-54, 2000.

ANDREOLA, F. et al. A cobertura vegetal de inverno e a adubação orgânica e, ou, mineral influenciando a sucessão feijão/milho. Revista Brasileira de Ciência do Solo, v.24, n.4, p.867-874, 2000.

AZEVEDO, D.M.P.; NASCIMENTO, H.T.S. Potencial forrageiro de espécies para cultivo no período de safrinha em solos de tabuleiros costeiros. Teresina: EMBRAPA, 2002. 4p. (Comunicado Técnico 148).

BOER, C.A. et al. Ciclagem de nutrientes por plantas de cobertura na entressafra em um solo de cerrado. Pesquisa Agropecuária Brasileira, v.42, n.9, p.1269-1276, 2007.

CALEGARI, A. Leguminosas para adubação verde de verão no Paraná. Londrina: IAPAR, 1995. 118p. (Circular, 80).

CALEGARI, A. Espécies para cobertura de solo. In: DAROLT, M.R. (Coord.). Plantio direto: pequena propriedade sustentável. Londrina: IAPAR, 1998. p.65-94. (Circular, 101).

CALEGARI, A. A importância da diversificação de culturas na recuperação e melhoria do solo e das pastagens. Disponível em: http://www.ensino.pr.senac.br/ Londrina/calegari/trabalho 3.htm . Acesso em: 05 jan. 2009.

CARNEIRO, M. A. C. et al. Produção de fitomassa de diferentes espécies de cobertura e suas alterações na atividade microbiana de solo de cerrado. Bragantia, v.67, n.2, p.455-462, 2008.

CARPENEDO, V.; MIELNICZUK, J. Estado de agregação e qualidade de agregados de Latossolo Roxo submetidos a diferentes sistemas de manejo. Revista Brasileira de Ciência do Solo, v.14, p.99-105, 1990.

CARVALHO, I.Q. et al. Espécies de cobertura de inverno e nitrogênio na cultura do milho em sistema de plantio direto. Scientia Agraria, v.8, n.2, p.179-184, 2007.

CATI. Nabo forrageiro, adubação verde para inverno. Informativo CATI n.25, 2000.

CERETTA, C.A. et al. Produção e decomposição de plantas invernais de cobertura de solo e milho, sob diferentes manejos da adubação nitrogenada. Ciência Rural, v.32, n.1, p.49-54, 2002.

DAROLT, M.R. Princípios para implantação e manutenção do sistema. In: DAROLT, M.R. Plantio direto: pequena propriedade sustentável. Londrina: IAPAR, 1998. p.16-45.

EMBRAPA - Empresa Brasileira de Pesquisa Agropecuária. Plataforma plantio direto. Disponível em: www.embrapa.br/plantiodireto.html Acesso em: 10 maio 2007. 
FAVERO, C. da et al. Modificações na população de plantas espontâneas na presença de adubos verdes. Pesquisa Agropecuária Brasileira, p.1355-1362, 2001.

FONTANELI, R.S. Capim italiano ou sorgo forrageiro? Semeie em mais de uma época e tenha melhor distribuição temporal de forragem. Embrapa/Centro Nacional de Pesquisa de Trigo. Notícia no 43/2001. Disponível em: http://www.cnpt.embrapa.br/not0143.htm. Acesso em: 23 de janeiro de 2003.

FORNASIERI FILHO, D. Manual da cultura do milho. Jaboticabal: FUNEP, 2007. 576p.

FORMENTINI, E.A. Cartilha sobre adubação verde e compostagem. Vitória: INCAPER, 2008. 27p.

FRANCISCO, E.A.B.; CÂMARA, G.M.S.; SEGATELLI, C.R. Estado nutricional e produção do capim pé-de-galinha e da soja cultivada em sucessão em sistema antecipado de adubação. Bragantia, v.66, n.2, p.259-266, 2007.

HAYASHI, M.M.S. et al. Balanço de energia da Crotalaria juncea L. no período seco e no período úmido do ano, em condições de cerrado. Revista Brasileira de Agrometeorologia, v.10, n.2, p.197-205, 2002.

KEARL, L.C. Nutrient requirements of ruminants in developing countries. Logan: Utah State University/ International Feedstuffs Institute, 1982. 381p.

KHATOUNIAN, C.A. Sobre adubos verdes e o manejo sustentável da biomassa. Revista Agroecologia, n.14, p.7-8, 2002.

KICHEL, A.N.; MIRANDA, C.H.B. Uso do milheto como planta forrageira. Gado de Corte Divulga, n.46, p.1-2, 2000.

LARA CABEZAS, W.A.R. et al. Influência da cultura antecessora e da adubação nitrogenada na produtividade de milho em sistema plantio direto e solo preparado. Ciência Rural, v.34, p.1005-1013, 2004.

LUCENA, Ricardo B. et al. Intoxicação por alcalóides pirrolizidínicos em ruminantes e equinos no Brasil. Pesquisa Veterinária Brasileira, v.30, n.5, p.447-452, 2010.

MASOJIDEK, J. et al. The synergetic effect of drought and light stress in sorghum and pearl millet. Plant Physiology, v.96, p.198-207, 1991.

MECHI, J. et al. Avaliação in vitro de alfafa, feijão guandu, mucuna cinza e mucuna preta. 1. Caracterização química. Centro de Energia Nuclear na Agricultura, CENA, USP. Disponível em: http://www.usp.br/siicusp/Resumos/14Siicusp/668.pdf. Acesso em: 01 set. 2010.

MEDEIROS, G.B.; CALEGARI, A. Sistema Plantio Direto com qualidade: a importância do uso de plantas de cobertura num planejamento cultural estratégico. Revista Plantio Direto. Edição 102. Novembro/dezembro de 2007. Disponível em:

http://www.plantiodireto.com.br/?body=cont_int;id=836. Acesso em: 18 fev. 2008. 
MELLO, D.F. et al. Avaliação do resíduo de nabo forrageiro extraído da produção de biodiesel como suplemento para bovinos de corte em pastagens. Revista Brasileira de Saúde e Produção Animal, v.9, n.1, p.45-56, 2008.

MESCHEDE, D.K.; FERREIRA, A.B.; RIBEIRO JÚNIOR, C.C. Avaliação de diferentes coberturas na supressão de plantas daninhas no cerrado. Planta Daninha, v.25, n.3, p.465471, 2007.

MINSON, D.J. Forage in ruminant nutrition. San Diego: Academic Press, 1990. 483p.

NAKAGAWA, J. et al. Intensidade de dormência durante a maturação de sementes de mucuna preta. Revista Brasileira de Sementes, v.29, n.1, p.165-170, 2007.

NASCIMENTO, J.T.; SILVA, I.F. da. Avaliação quantitativa e qualitativa da fitomassa de leguminosas para uso como cobertura de solo. Ciência Rural, v.34, n.3, p.947-949, 2004.

NRC. NATIONAL RESEARCH COUNCIL - NRC. Nutrient requeriments of dairy cattle. 6.rev.ed. Washinton, D.C.: 1989. 157p.

OLIVEIRA, J.B. et al. Mapa pedológico do Estado de São Paulo: legenda expandida. Campinas, Instituto Agronômico/EMBRAPA-Solos. Campinas. 1999. 64p.

PORTUGAL, A.F. et al. Rendimento de matéria seca e proteína de cultivares de sorgo forrageiro no primeiro corte e na rebrota. Revista Ceres, v.50, n.289, p.357-366, 2003.

ROLIM, G.S. et al. Classificação climática de Köppen e de Thornthwaite e sua aplicabilidade na determinação de zonas agroclimáticas para o estado de São Paulo. Bragantia, v.66, n.4, p.711-720, 2007.

SAKAI, R.H. et al. Avaliação agronômica de quatro espécies de mucuna utilizadas como adubos verdes em sistema agroecológico. Revista Brasileira de Agroecologia, v.2, n.1, p.910-913, 2007.

SANTOS, J.W. dos et al. Níveis de grão de capim-pé-de-galinha (Eleusine coracana) em dietas para ovinos: consumo e digestibilidade. Revista Brasileira de Zootecnia, v.37, n.10, p.1884-1889, 2008.

SANTOS, V.S. dos; CAMPELO JUNIOR, J.H. Influência dos elementos meteorológicos na produção de adubos verdes, em diferentes épocas de semeadura. Revista Brasileira de Engenharia Agrícola e Ambiental, v.7, n.1, p.91-98, 2003.

SCHEFFER-BASSO, S.M.; AGRANIONIK, H; FONTANELI, R.S. Acúmulo de biomassa e composição bromatológica de milhetos das cultivares comum e africano. Revista Brasileira de Agrociência, v.10, n.4, p.483-486, 2004.

SEGATELLI, C.R. et al. Producción de materia seca de mijo africano (Eleusine coracana (L.) Gaertn.) sobre sistema de abono anticipado de soya. Interciencia, v.33, n.7, p.542-546, 2008.

SENO, M.S., GOMES, L. CORTELAZZO, A.L. Caracterização do material de reserva em feijão-guandu. lablabe e mucuna. Bragantia. v.55, n.1, p. 57-65, 1996. 
SILVA, D. J. Análise de alimentos: métodos químicos e biológicos. 2 ed. $1^{\text {a }}$ reimpressão. Viçosa: Imprensa Universitária, 1998. 165p.

SODRÉ FILHO, J. et al. Culturas de sucessão ao milho na dinâmica populacional de plantas daninhas. Scientia Agraria, v.9, n.1, p.7-14, 2008.

SUZUKI, L.E.A.S.; ALVES, M.C. Fitomassa de plantas de cobertura em diferentes sucessões de culturas e sistemas de cultivo. Bragantia, v.65, n.1, p.121-127, 2006.

TORRES, J.L.R.; PEREIRA, M.G.; FABIAN, A.J. Produção de fitomassa por plantas de cobertura e mineralização de seus resíduos em plantio direto. Pesquisa Agropecuária Brasileira, v.43, n.3, p.421-428, 2008.

VALADARES FILHO, S.C. et al. Tabelas brasileiras de composição de alimentos para bovinos. Viçosa: UFV, 2006. 329p.

VIEIRA, R.F.; VIEIRA, C.; VIEIRA, R.F. Leguminosas graníferas. Viçosa: UFV, 2001. 206p. 